\title{
Tidal ice dynamics in the area of Svalbard and Frans Josef Land
}

\author{
N. E. DMITRIEV, A. YU. PROSHUTINSKY, T. B. LøYNING and T. VINJE
}

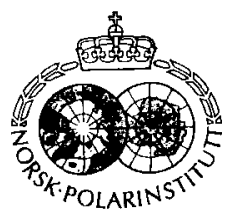

\begin{abstract}
Dmitriev, N.E., Proshutinsky, A. Yu., Løyning, T.B. \& Vinje. T. 1991: Tidal ice dynamics in the area of Svalbard and Frans Josef Land. Polar Research 9(2), 193-205.

This study is part of the Soviet-Norwegian Oceanographic Programme (SNOP) on icc and water dynamics in the region between Svalbard and Frans Josef Land. The effects of the movements of water and ice on the ice regime are discussed. Due to the scarcity of data, numerical hydrodynamical simulations are used

The tidal ice drift is visualized on satellite images as elliptically shaped traces in the ice fields formed by grounded icebergs. These traces are a result of the joint action of tides, wind and permanent currents.

N. E. Dmitriev and A. Yu. Proshutinsky, Arctic and Antarctic Scientific Research Institute, Bering st. 38. St. Petersburg 199226, U.S.S.R.; T. B. Løyning and T. Vinje. Norsk Polarinstitutt, P.O. Box 158, N-1330 Oslo Lufthavn, Norway.
\end{abstract}

\section{Introduction}

This study is part of the Soviet-Norwegian Oceanographic Programme (SNOP) on ice and water dynamics in the region between Svalbard and Frans Josef Land. The effects of the movements of water and ice on the ice regime are discussed. Due to the scarcity of data, numerical hydrodynamical simulations are used.

The tidal ice drift is visualized on satellite images (Figs. 1 and 2) as elliptically-shaped traces in the ice fields formed by grounded icebergs. The length, form and orientation of the elliptic axis make it possible to determine some important parameters which can accordingly be used for the calibration of the mathematical models.

Two different methods have previously been used for tidal ice drift estimation. Zubov (1945) and Legenkov (1968) assumed the ice motion to be determined by the surface currents only. They calculated deformation in the ice cover to specify the regional and temporal change of the ice concentration. Kagan (1968), Kheysin \& Ivchenko (1973), Kowalik (1981), and Timokhov \& Khey$\sin (1987)$ took into account the additional effects of the ice cover and formulated a coupled model. Kagan (1968) considered a three-layer model with near-bottom and near-ice boundary layers, and a central layer where the turbulence was neglected. The lack of knowledge of frictional forces in the central layer prevent us from using this model for studies in the Arctic oceans where the frequency of the major tide-generating force M2 is equal or very close to the inertial frequency.
Kowalik (1981) offered a non-linear twodimensional model, which was based on shallow water theory and coupled with a non-linear icemodel. His model took into account the internal shear in the ice cover. This model has been used in this study to simulate the tides and the corresponding ice drift.

The ice and weather conditions, the area covered by satellite images, and the area covered by the model are all shown in Fig. 3.

\section{The model}

The horizontal momentum equation for the water, according to shallow water theory and with the tide producing forces included, is

$$
\begin{aligned}
\frac{\mathrm{d} \mathbf{U}}{\mathrm{dt}}+2 \boldsymbol{\Omega} \times \mathbf{U}= & -\operatorname{mg} \nabla\left(\alpha \xi-\beta \xi^{+}\right) \\
& +A \mathrm{~m}^{2} \nabla^{2} \mathbf{U}-\frac{1}{\rho_{\mathrm{w}} \mathrm{H}}\left(\tau_{\mathrm{b}}-\tau_{\mathrm{i}} \mathrm{S}\right)
\end{aligned}
$$

The continuity equation on the integral form is

$$
\frac{\partial \xi}{\partial t}=-m^{2} \operatorname{div}\left(\frac{U}{m} H\right) .
$$

The equation of the ice motion is

$$
\frac{\mathrm{dU}_{\mathrm{i}}}{\mathrm{dt}}+2 \boldsymbol{\Omega} \times \mathbf{U}_{\mathrm{i}}=-\operatorname{mg} \nabla \xi+\frac{\boldsymbol{\tau}_{\mathrm{i}}}{\tilde{\rho}}+\mathbf{F}_{\mathrm{i}}
$$




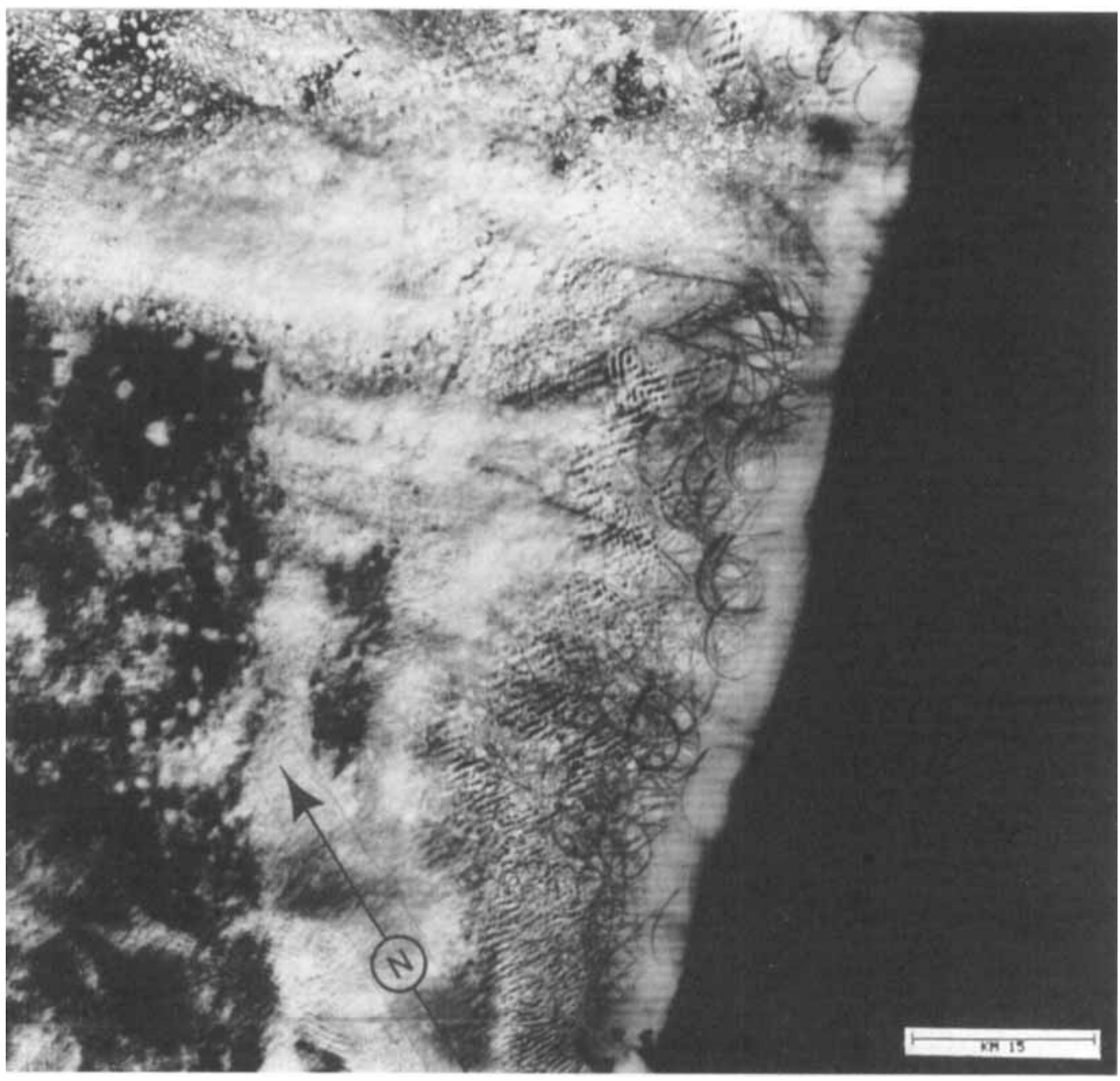

Fig. 1. Satcllite image of ice situation on 21 May 1988.

and the equation for the ice concentration is

$$
\frac{\partial S}{\partial t}=-m^{2} \operatorname{div}\left(\frac{U_{i}}{m} S\right) .
$$

$\mathbf{U} . \mathbf{U}_{\mathrm{i}}$ are the horizontal velocity vectors of water and ice,

$t$ is the time variable.

$\nabla$ is the horizontal del operator,

$H$ is the depth; $H=D+\xi$. where $D$ is the equilibrium depth of the ocean:

$\xi$ is the displacement of the sea surface from its equilibrium position,

$\xi^{+}$is the equilibrium tide: $a$ is a coefficient which takes into account the effects of increased water mass on the solid earth, i.e. depression due to higher sea level and uplift due to tide producing forces (the changes of the phases are neglected). $\alpha=1$ is used in the model simulation.

$\beta$ is a reduction coefficient, which parametrizes the effect of tidal forces on an elastic earth. $\beta=$ 0.69 is used in the model simulation.

$F_{i}$ is the internal ice friction (forces of interaction between ice floes),

$\mathrm{m}$ is a scale coefficient for the set approximating the Arctic Ocean on the stereographic projection map. For our map $m=1.0$ on the North 


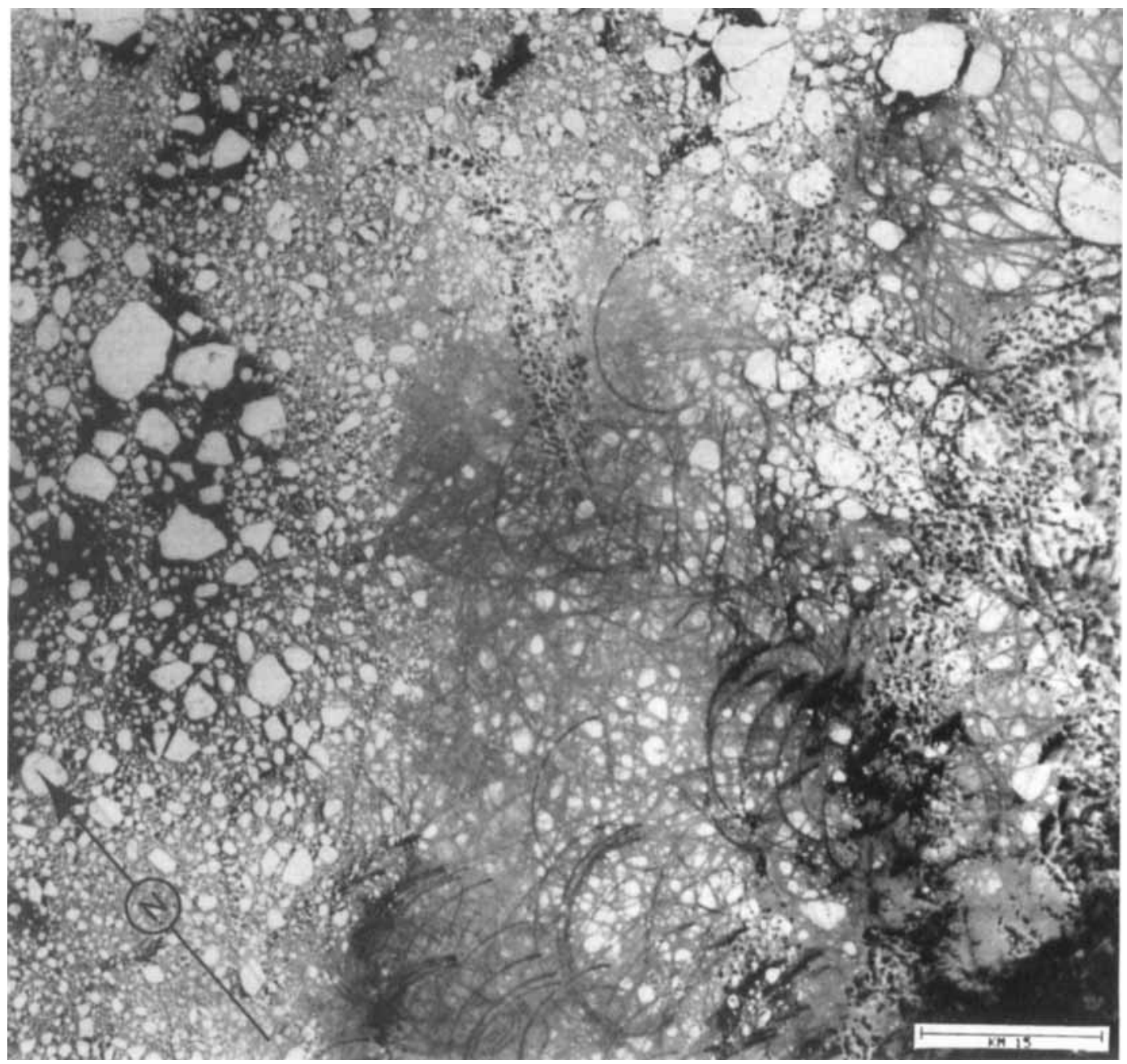

Fig. 2. Satcllite image of ice situation on 1 June 1988.

Pole, $\mathrm{m}=1.017$ at latitude $75^{\circ} \mathrm{N}$ and $\mathrm{m}=1.072$ at latitude $60^{\circ} \mathrm{N}$.

$\rho_{w}$ is the density of water,

$\bar{\rho}$ is the surface density of the ice cover where $\bar{\rho}=\rho_{\mathrm{i}} \mathrm{h}, \mathrm{S}, \rho_{\mathrm{i}}, \mathrm{h}_{\mathrm{i}}$ and $\mathrm{S} \mathrm{i}_{\mathrm{i}}$ are the density, thickness and concentration of the sea ice respectively;

$A$ is the coefficient of the horizontal eddy viscosity.

$\Omega$ is the angular velocity of the earth's rotation, $\mathrm{g}$ is the magnitude of acceleration due to gravity.

The bottom and ice-water stress vectors $\tau_{\mathrm{b}}$ and $\tau_{\mathrm{i}}$ can be expressed by

$\tau_{\mathrm{b}}=\mathrm{K}_{\mathrm{b}} \rho_{\mathrm{w}} \mathbf{U}|\mathbf{U}|, \quad \tau_{\mathrm{i}}=\mathrm{K}_{\mathrm{i}} \rho_{\mathrm{w}}\left|\mathbf{U}-\mathbf{U}_{\mathrm{i}}\right|\left(\mathbf{U}-\mathbf{U}_{\mathrm{i}}\right)$ where $K_{b}$ and $K_{i}$ are bottom and ice-water friction coefficients.

The equation for the internal ice friction is

$\mathbf{F}_{\mathrm{i}}=\eta \nabla^{2} \mathbf{U}_{\mathrm{i}}+\gamma \nabla \operatorname{div} \mathbf{U}_{\mathrm{i}}-\nabla \mathrm{P}$,

$\mathbf{P}= \begin{cases}-\mathbf{K}_{\mathrm{p}} \operatorname{div} \mathbf{U}_{\mathrm{i}} & \text { if } \operatorname{div} \mathbf{U}_{\mathrm{i}} \geq 0 \\ 0 & \text { if } \operatorname{div} \mathbf{U}_{\mathrm{i}}<0\end{cases}$

Where $\eta$ and $\gamma$ are the coefficients of bulk and shear viscosity in the ice cover with units in $\mathrm{cm}^{2} / \mathrm{s}, \quad P$ is the pressure due to the ice compression, $\mathrm{K}_{\mathrm{p}}$ is the coefficient of compression. We borrowed the $F_{;}$from the studies of Rothrock (1975) and Kowalik (1981). 
196 N. E. Dmitriev et al.
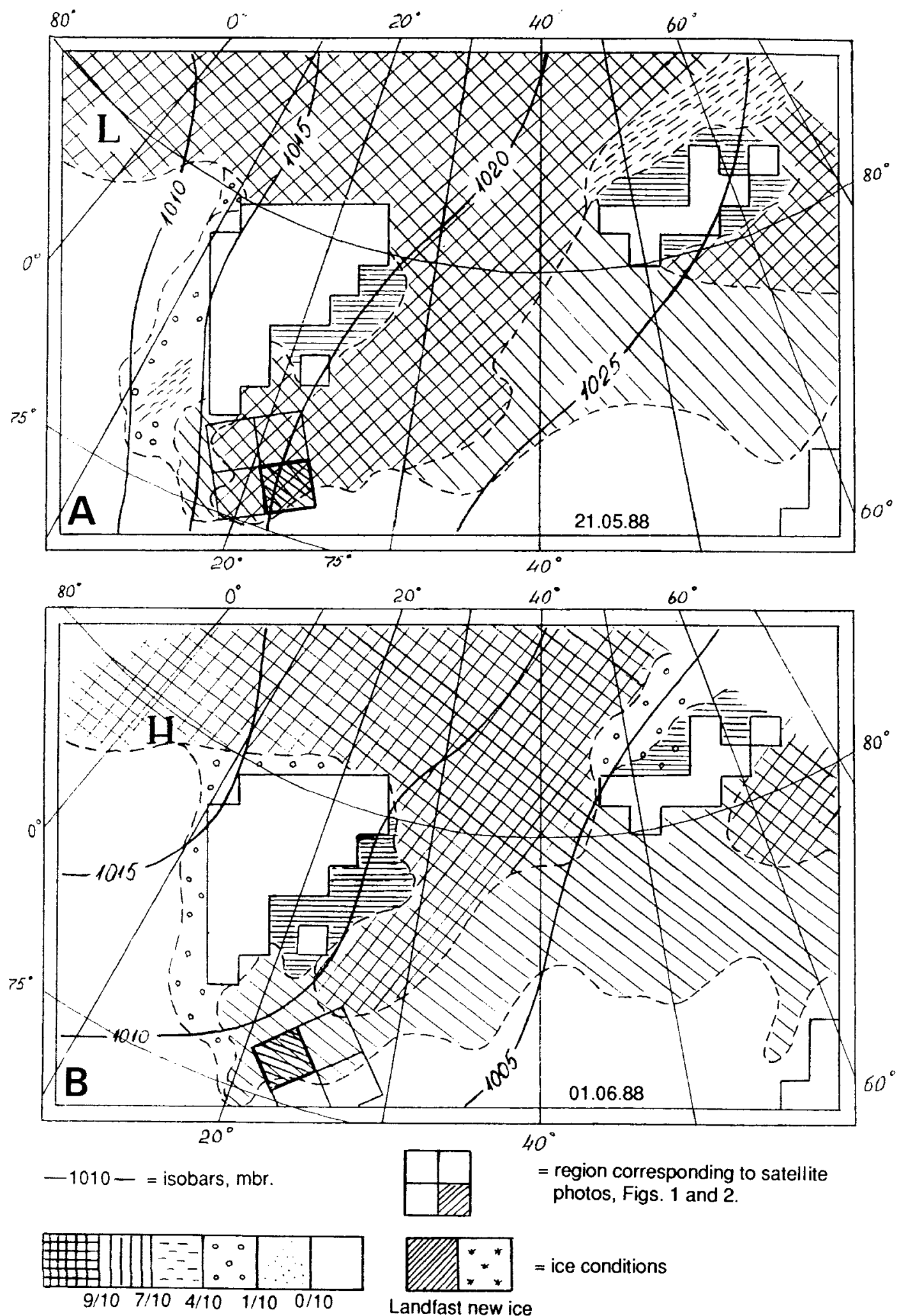


\section{Boundary and initial conditions}

At the coasts $\left(G_{1}\right)$ we have used a no-slip condition, i.e. zero velocities, along the coastlines

$\mathbf{U}_{\mid \mathrm{G}_{1}}=0, \mathbf{U}_{\mathrm{i} \mid \mathrm{G}_{1}}=0$

Along the open boundary $\left(G_{2}\right)$ the vector of the average velocity must be known as a function of position and time.

Let $\mathbf{U}=(u, v)$ and $\mathbf{U}_{i}=\left(u_{i}, v_{i}\right)$ then

$\mathrm{u}(\mathrm{x}, \mathrm{y}, \mathrm{t})_{\mid \mathrm{G}_{2}}=\mathrm{A}_{\mathrm{u}} \cos \left(\omega \mathrm{t}-\psi_{\mathrm{u}}\right)$

$v(\mathrm{x}, \mathrm{y}, \mathrm{t})_{\mid \mathrm{G}_{2}}=\mathrm{A}_{\mathrm{v}} \cos \left(\omega \mathrm{t}-\psi_{\mathrm{v}}\right)$

$\mathrm{u}_{\mathrm{i}}(\mathrm{x}, \mathrm{y}, \mathrm{t})_{\mathrm{G}_{2}}=\mathrm{A}_{\mathrm{u}_{\mathrm{i}}} \cos \left(\omega \mathrm{t}-\psi_{\mathrm{u}_{\mathrm{i}}}\right)$

$v_{i}(\mathrm{x}, \mathrm{y}, \mathrm{t})_{\mid \mathrm{G}_{2}}=\mathrm{A}_{\mathrm{v}_{\mathrm{i}}} \cos \left(\omega \mathrm{t}-\psi_{\mathrm{v}_{\mathrm{i}}}\right)$

with the following condition, which means that the water mass and masses of ice are conserved in the basin:

$\int \oint_{G_{2}} u_{n} d G d t=0, \int \oint_{G_{2}} u_{n i} d G d t=0$

$\mathrm{u}_{\mathrm{n}}=v \sin \alpha_{1}+v \cos \alpha_{1}$.

$\mathrm{u}_{\mathrm{ni}}=v_{\mathrm{i}} \sin \alpha_{1}+v_{\mathrm{i}} \cos \alpha_{1}$

where $\mathrm{n}$ is a normal to the open boundary, $\omega$ is a frequency of the tidal wave, $\psi_{\mathrm{u}}, \psi_{\mathrm{v}}, \psi_{\mathrm{ui}}, \psi_{\mathrm{vi}}$ are the phases of water and ice velocity and $A_{u}$, $A_{v}, A_{u i}, A_{v i}$ are the amplitudes of ice and water velocities, respectively. $\alpha_{1}$ is the angle between the $\mathrm{n}$ and $\mathrm{X}$-axis and $\mathrm{dG}$ is an infinitesimal segment of $G_{2}$. We assumed the system to be initially at rest,

$$
\begin{array}{r}
\mathbf{U}(x, y, 0)=0, \quad \mathbf{U}_{i}(x, y, 0)=0, \\
z(x, y, 0)=0 \text { at } t=0
\end{array}
$$

and the ice concentration to be

$S(x, y, 0)=0.9$ at $t=0$.

\section{Results}

In the numerical simulations reported below, we have used the boundary values for $A_{u}, \psi_{u}, A_{u i}$, $\psi_{\mathrm{ui}}$ obtained by Polyakov \& Proshutinsky (1988). Equations 1 to 4 were approximated by a Lax-Wendroff semi-implicit, central-difference scheme, modified by Tee (1976).

Fig. 3. Ice and meteorological situation in the region on 21.05 .88 (A) and $01.06 .88(\mathrm{~B})$.
The model parameters used for the simulation are

$\Delta=55555 \mathrm{~m}$ grid size,

$\mathrm{K}_{\mathrm{b}}=2.6 \cdot 10^{-3}$ bottom friction drag coefficient,

$\mathrm{K}_{\mathrm{i}}=5.5 \cdot 10^{-3}$ ice-water friction drag coefficient, $\mathrm{A}=10^{4} \cdot \mathrm{D} \mathrm{m}^{2} / \mathrm{s}$,

$h_{i}=250 \mathrm{~cm}$ average ice thickness value in the Arctic Basin,

$h_{i}=450 \mathrm{~cm}$ average ice thickness value in the Canadian sector,

$h_{i}=140 \mathrm{~cm}$ average ice thickness value in the marginal seas,

$\eta=10^{8}$ coefficient of bulk viscosity,

$\gamma=10^{8}$ coefficient of shear viscosity,

$\mathrm{K}_{\mathrm{p}}=10 \eta$ coefficient of compression.

Polyakov \& Proshutinsky (1988) obtained rootmean-square errors for the values of the tidal amplitudes and phases, using observed harmonic constants for 94 stations located on the coast and islands of the Arctic oceans. These values are $0.054 \mathrm{~m}, 0.023 \mathrm{~m}, 0.013 \mathrm{~m}$ and $0.014 \mathrm{~m}$ from amplitudes of the waves M2, S2, K1 and O1. respectively. The standard deviations for the phases are 26, 28, 28, 30 degrees, respectively. There is a lack of tidal observations in the region of Spitsbergen and Frans Josef Land. Most stations are situated in the narrow bays or straits far from the open ocean. One station. located in the strait between Nordaustlandet and Kvitøya (Aagard et al. 1983) provides data on bottom pressure and current records (Tables 1 and 2). Apparently, the observed harmonic constants for most of the stations do not reflect the real process of spreading of the tidal waves in the ocean (Figs. 4 and 5). The tidal currents in the Fram Strait (Table 1) are assumed to be more representative and they are in closer correspondence with the calculated values.

We observe many features in our cotidal charts (Figs. 4 and 5) of waves M2 and K1 common to those obtained by Gjevik \& Straume (1989). The main differences are related to the displacement of the amphidromic point of the M2 wave near Franz Josef Land and Novaja Zemlja. Our charts indicate that these points are in the open sea (two grid steps from the coast) while the charts of Gjevik \& Straume (1989) indicate a location on the coast. The differences are due to different grid implimentation.

The study of Polyakov \& Proshutinsky (1988) shows that the Barents Sea is a good resonater of the semidiurnal oscillations. Small differences in 
Table 1. Tidal ellipse parameters in the Fram Strait. Abbrevations: $M o d=$ model results; obs = observations; res $=$ our results Model results are from Gjevik (1990), observations (F1, F2. F3) arc from Aagard et al. (1985), and (F4) is from Aagard et al. (1983) * indicates upper current recorder: ${ }^{* *}$ indicates near bottom current recorder. The geographical positions of the stations F1, F2. F3 and F4 are given in Table 3.

\begin{tabular}{|c|c|c|c|c|c|c|c|c|}
\hline Station & Consistuent & & \multicolumn{3}{|c|}{$\begin{array}{l}\text { Major semiaxis } \\
\mathrm{cm} / \mathrm{s}\end{array}$} & \multicolumn{3}{|c|}{$\begin{array}{l}\text { Minor semiaxis } \\
\mathrm{cm} / \mathrm{s}\end{array}$} \\
\hline \multirow[t]{2}{*}{$\mathrm{F} 1$} & $\mathbf{M}_{2}$ & & 3.3 & 2.5 & 3.3 & 0.2 & 0.4 & 0.6 \\
\hline & $\mathrm{K} 1$ & & 1.5 & 1.1 & 1.7 & 0.4 & 0.2 & 0.3 \\
\hline \multirow[t]{2}{*}{$\mathrm{F} 2$} & $\mathrm{M}_{2}$ & & 2.6 & 2.5 & 2.8 & 0.2 & 0.2 & 0.4 \\
\hline & KI & & 1.3 & 1.2 & 1.6 & 0.3 & 0.3 & 0.0 \\
\hline \multirow[t]{2}{*}{$\mathrm{F} 3$} & $\mathbf{M} 2$ & & 2.5 & 2.5 & 2.4 & 0.2 & 0.2 & 0.4 \\
\hline & $\mathrm{K} 1$ & & 1.2 & 1.4 & 1.5 & 0.1 & 0.1 & 0.1 \\
\hline \multirow[t]{2}{*}{$\mathrm{F} 4$} & M2 & $*$ & & 8.6 & 7.9 & & 2.2 & 3.4 \\
\hline & & $* *$ & & 3.6 & & & 2.4 & \\
\hline \multirow[t]{2}{*}{$\mathrm{F} 4$} & $\mathrm{~K} 1$ & $*$ & & 1.3 & 1.3 & & 0.1 & 0.1 \\
\hline & & $* *$ & & 0.9 & & & 0.2 & \\
\hline \multirow[t]{2}{*}{ F4 } & $\mathrm{S} 2$ & $*$ & & 3.5 & 3.2 & & 1.3 & 1.1 \\
\hline & & $* *$ & & 1.6 & & & 0.7 & \\
\hline \multirow[t]{2}{*}{$\mathrm{F} 4$} & $\mathrm{Ol}$ & $*$ & & 0.5 & 0.5 & & 0.2 & 0.3 \\
\hline & & $* *$ & & 0.3 & & & 0.0 & \\
\hline
\end{tabular}

Table 2. Tidal elipse parameters in the Fram Strait. Abbrevations: Mod $=$ model results; obs $=$ observations; res $=$ our results. Model results are from Gjevik (1990), observations (F1. F2. F3) are from Aagard et al. (1985), and (F4) is from Aagard et al. (1983). Azimuth $=$ orientation in degrees of major axis from north, positive eastward. Rotation: positive $(+)=$ anticyclonic; negative $(-)=$ cyclonic. ${ }^{*}$ indicates upper current recorder: ** indicates near bottom current recorder.

\begin{tabular}{|c|c|c|c|c|c|c|c|c|}
\hline \multirow[b]{2}{*}{ Station } & \multirow[b]{2}{*}{ Consistuent } & & \multicolumn{3}{|c|}{ Azimuth degree } & \multicolumn{3}{|c|}{ Rotation } \\
\hline & & & Mod & Obs & Res & Mod & Obs & Res \\
\hline \multirow[t]{2}{*}{$\mathrm{F} 1$} & $\mathrm{M} 2$ & & 13 & 18 & 10 & + & + & + \\
\hline & K1 & & -11 & -37 & -14 & - & - & - \\
\hline \multirow[t]{2}{*}{$\mathrm{F} 2$} & M2 & & 10 & 14 & 0 & + & + & + \\
\hline & KI & & 1 & 19 & 15 & - & - & - \\
\hline \multirow[t]{2}{*}{ F3 } & M2 & & 16 & 8 & 17 & + & + & + \\
\hline & $\mathrm{K} 1$ & & 2 & -6 & 6 & - & - & - \\
\hline \multirow[t]{2}{*}{ F4 } & $\mathrm{M}^{2}$ & $*$ & & -6 & -8 & & + & + \\
\hline & & $* *$ & & -12 & & & - & \\
\hline \multirow[t]{2}{*}{ F4 } & $\mathrm{K} 1$ & $*$ & & -14 & 15 & & + & + \\
\hline & & $* *$ & & -27 & & & - & \\
\hline \multirow[t]{2}{*}{$\mathrm{F} 4$} & $\mathrm{~S} 2$ & $*$ & & -15 & 12 & & + & + \\
\hline & & $* *$ & & 51 & & & - & \\
\hline \multirow[t]{2}{*}{$\mathrm{F} 4$} & $\mathrm{Ol}$ & $*$ & & -57 & 10 & & + & + \\
\hline & & $* *$ & & -68 & & & + & \\
\hline
\end{tabular}

Table 3. Geographical positions of the stations.

\begin{tabular}{lcr}
\hline Station & $\begin{array}{c}\text { Station Coordinates } \\
\text { Lat }\end{array}$ & \multicolumn{1}{l}{ Lon } \\
\hline F1 & $78^{\circ} 59^{\prime} \mathrm{N}$ & $5^{\circ} 15^{\prime} \mathrm{E}$ \\
F2 & $79^{\circ} 00^{\prime} \mathrm{N}$ & $4^{\circ} 25^{\prime} \mathrm{E}$ \\
F3 & $78^{\circ} 55^{\prime} \mathrm{N}$ & $3^{\circ} 18^{\prime} \mathrm{E}$ \\
F4 & $80^{\circ} 00^{\prime} \mathrm{N}$ & $30^{\circ} 00^{\prime} \mathrm{E}$ \\
\hline
\end{tabular}

the approximation of depths of coastline between the different models may therefore lead to considerable differences in the cotidal charts.

The calculated tidal ice drift (Figs. 6 and 7) shows maximum velocities to the south of Spitsbergen, at depths from $50 \mathrm{~m}$ to $100 \mathrm{~m}$. The velocity of the semidiurnal ice drift is in this area about $30 \mathrm{~cm} / \mathrm{s}$. The ice velocities caused by the 

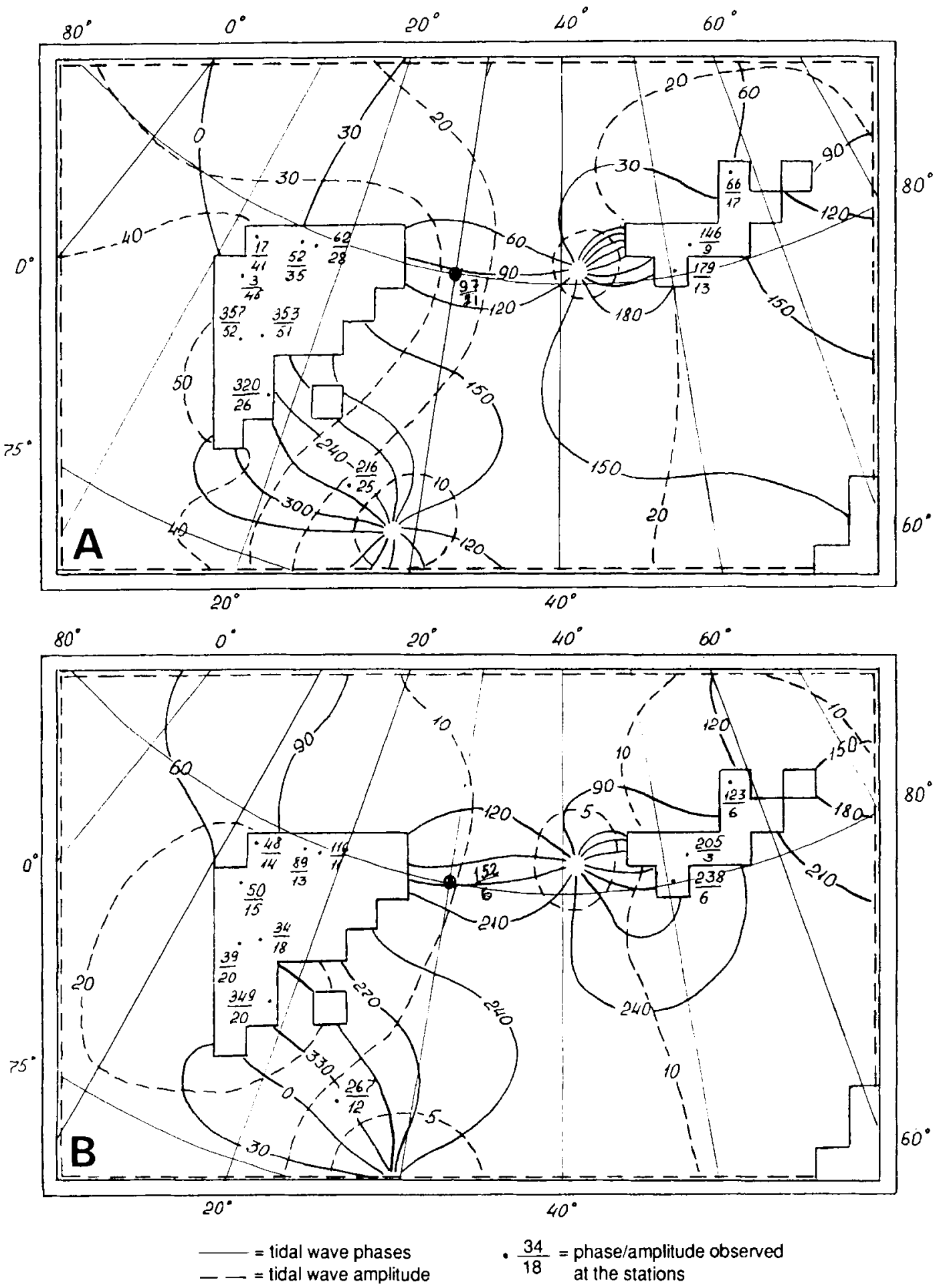

Fig. 4. Phases and amplitudes of the M2 (A) and S2 (B) tidal waves. Zero phase corresponds to the lunar time at the Greenwich Meridian. Phases are in degrees, amplitudes in $\mathrm{cm}$.

- $\frac{152}{6}=$ phase/amplitude observed by pressure recorder 
200 N. E. Dmitriev et al.
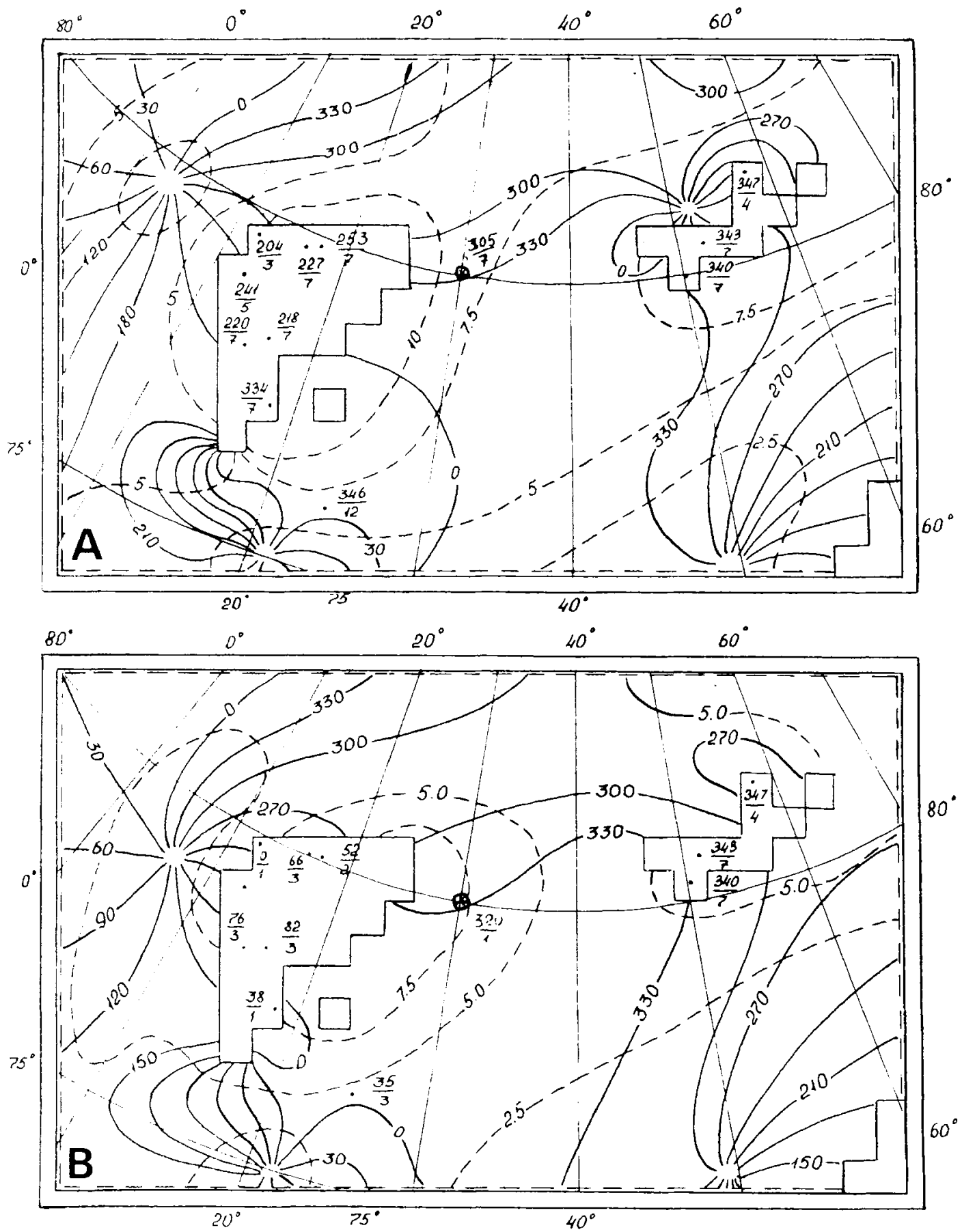

- $=$ tidal wave phases

$-{ }_{-}=$tidal wave amplitude

Fig. 5. Phases and amplitudes of the $\mathrm{K} 1$ (A) and $\mathrm{Ol}$ (B) tidal waves. Amplitudes are in $\mathrm{cm}$.

\section{$\frac{.204}{3}=$ phase/amplitude observed at the stations}

$\frac{320}{1}=$ phase/amplitude observed by pressure recorder 

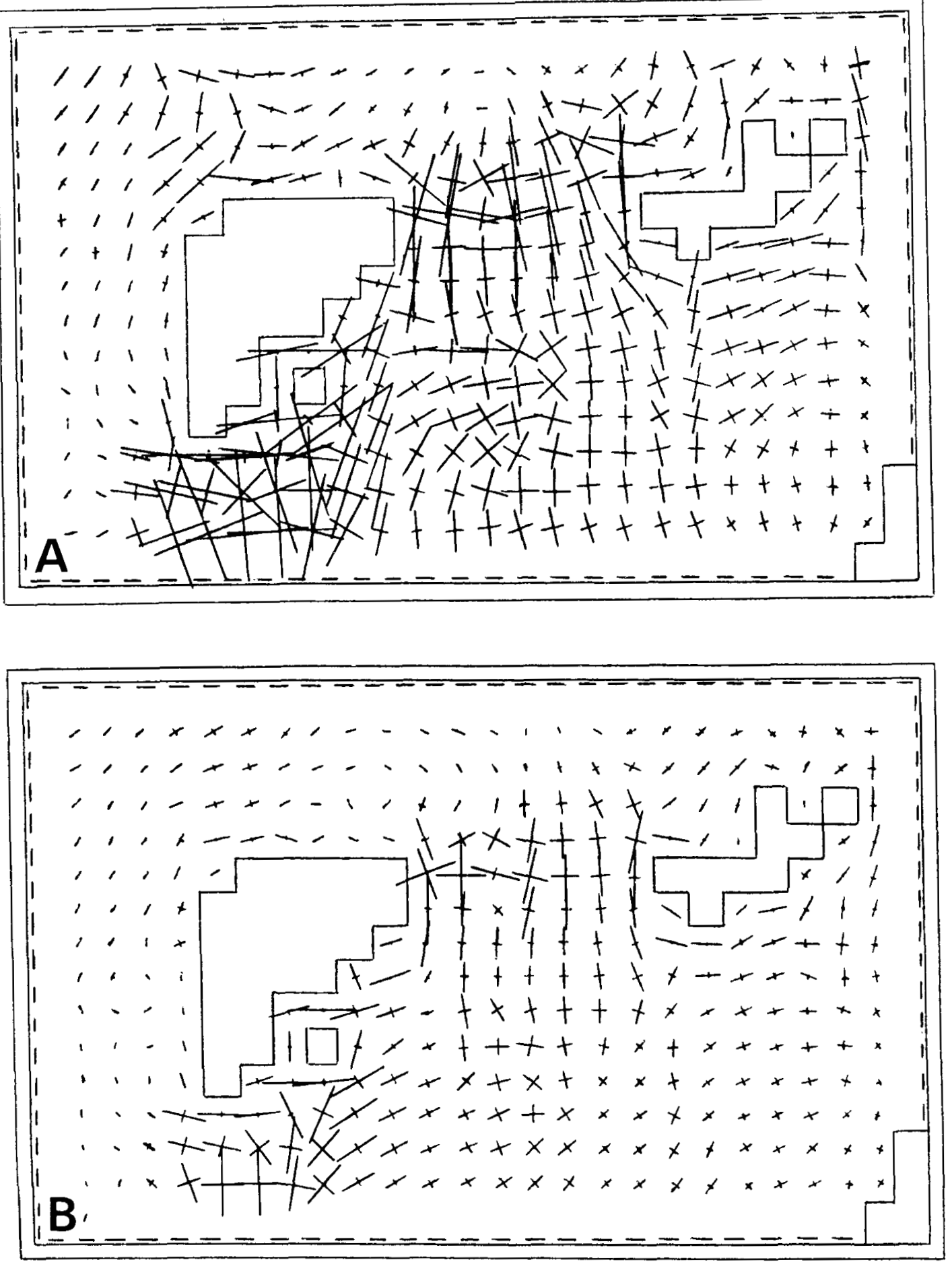

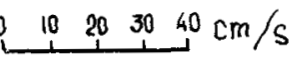

Fig. 6. Principal axis of M2 (A) and S2 (B) tidal ice motion ellipse. 

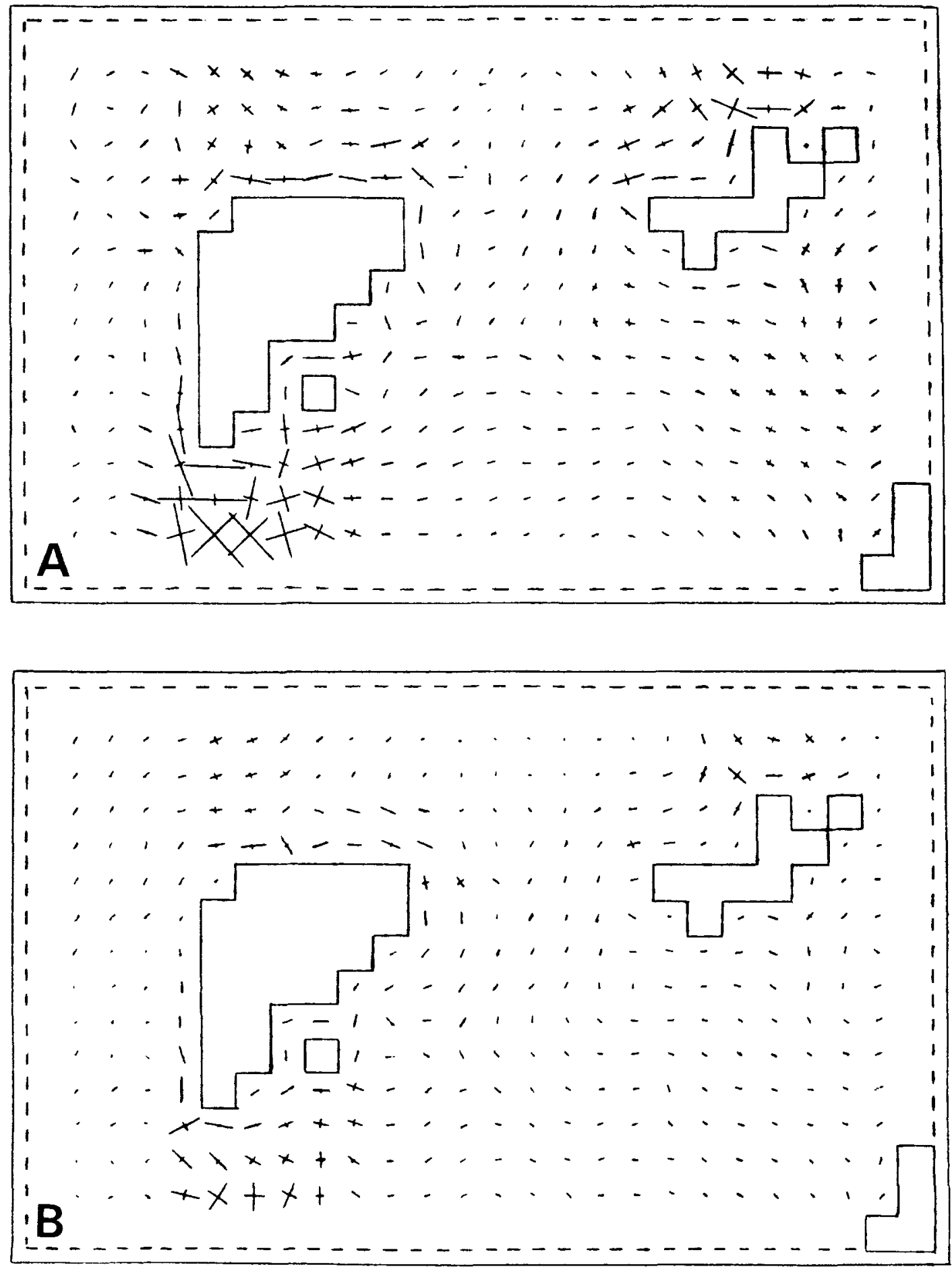

\section{$\underbrace{0.1020 \quad 3040} \mathrm{~cm} / \mathrm{s}$}

Fig. 7. Principal axis of the $\mathrm{K} 1$ (A) and $\mathrm{O}$ ( $\mathrm{B}$ ) tidal ice motion ellipse 

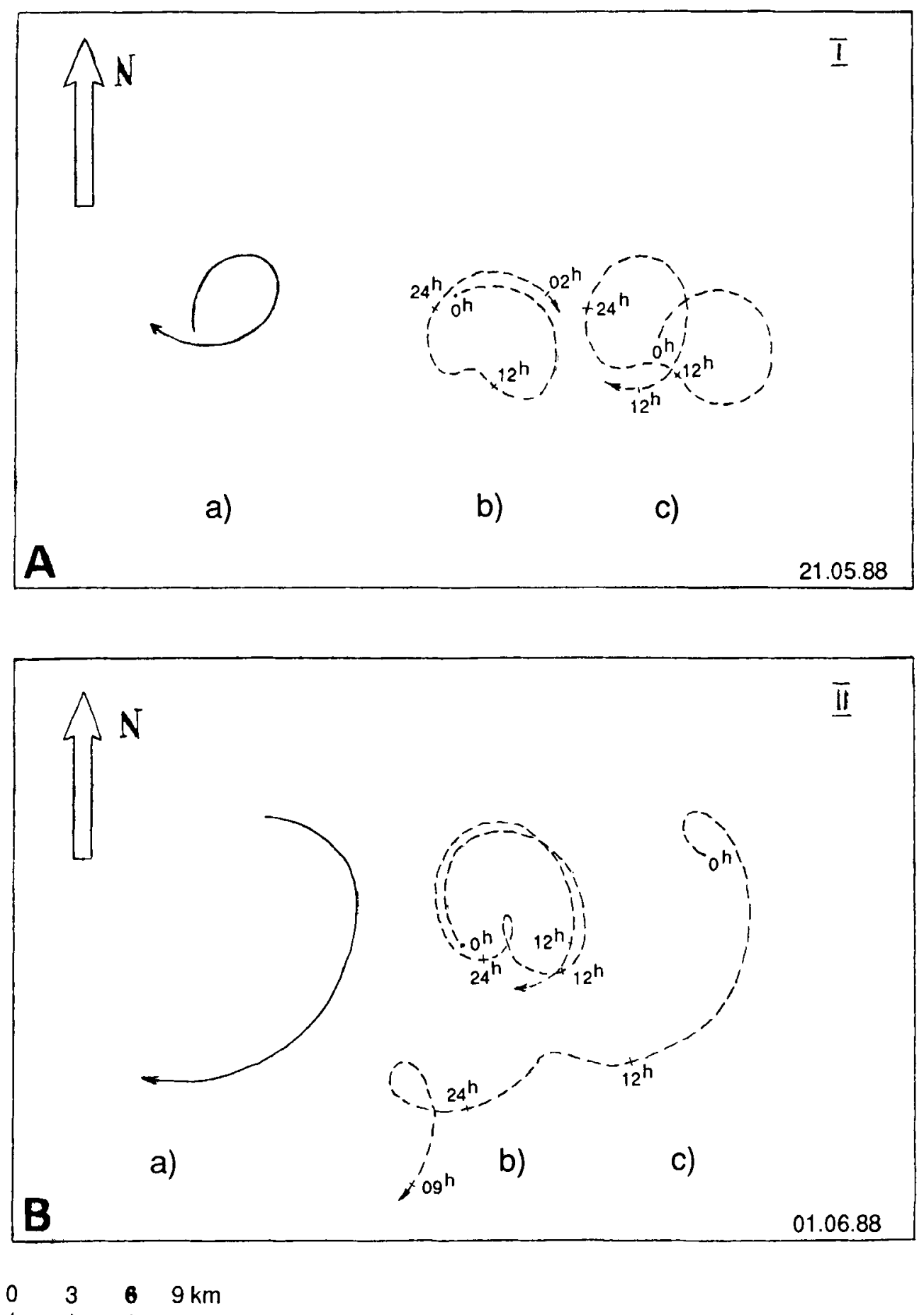

Fig. 8. Trajectories of ice motions. a) $=$ observed data where A corresponds to Fig. 1 and B corresonds to Fig. 2 . b) $=$ calculated results, where ice velocities and the sum of the harmonic tidal wave components $\mathrm{M} 2, \mathrm{~S} 2, \mathrm{~K} 1$ and $\mathrm{O} 1 \mathrm{have}$ been used. c) $=$ calculated results as b) plus the influence of wind and permanent currents. 


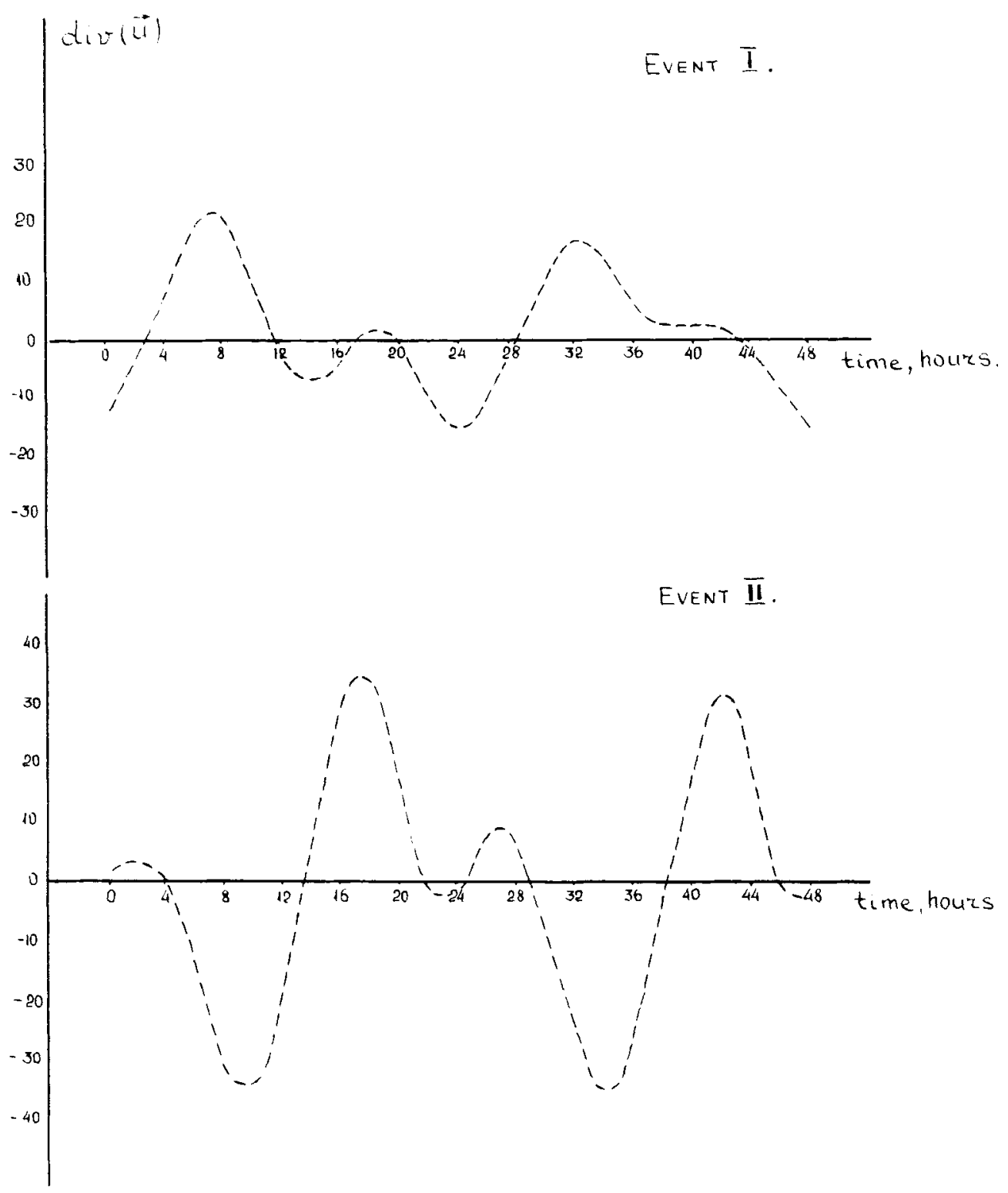

Fig. 9. The divergence of the ice velocities for the situation on 21 May 1988 (Event I) and for the situation on 1 June 1988 (Event II).

diurnal K1 wave are greater or equal to the effects of the semidiurna! $\$ 2$ wave.

The intensification of the semidurnal ice drift is noticeable in the area between Frans Josef Land and Spitsbergen. The velocities of the net diurnal ice drift is. however, relatively small and possibly directed northwards between Spitsbergen and Frans Josef Land. The main direction of the maxi- mum ice drift deviates from 8 to 30 degrees from the main direction of the maximum water velocities in the region.

Now let us discuss the correspondence between the calculated ice drift and the observed drift (Figs. 1 and 2). We will then analyse the character of the ice drift and specify the ice and meteorological conditions. 
On 21 May (Fig. 1) the ice concentration was $9-10 / 10$. The ice border was well-defined and the ice was in a compressive condition because of normal directed, on-ice winds. In this situation, apparently, there were no discernible windinduced movements of the ice cover. The orientation of the most elliptical trajectory was parallel to the ice border. The average length of the major axis was $5.8 \mathrm{~km}$ and the minor axis about $3.9 \mathrm{~km}$. The trajectories of the ice drift were unclosed with a small distance from the beginning to the end of the track. If we assume that the semidiurnal tidal icedrift prevailed in this region, then the average permanent current velocity must have been equal to $4 \mathrm{~cm} / \mathrm{s}$ and directed to the west. This current may be related with the general anticyclonic circulation of the seawater around Spitsbergen. Fig. 8A and B show (a) observed trajectory, (b) calculated trajectory with only the tidal forces included in the model, and (c) calculated trajectory with tidal forces, the wind and permanent current included. The model calculations are carried out for two tidal periods. This explains why there are two loops in the model results (Fig. $8 \mathrm{~A}(\mathrm{~b}), \mathrm{B}(\mathrm{b})$, and $\mathrm{B}(\mathrm{c})$ ) and not in the observations (Fig. $8 \mathrm{~A}(\mathrm{a})$ and $\mathrm{B}(\mathrm{a})$ ).

The trajectories are obtained by using current hourly values from the model calculations to calculate the particle displacement. Nilsen et al. (1990) employed a simular procedure, using current measurements averaged over a period of 30 minutes.

Fig. 8A reveals that good correspondence between the model calculation and observations is obtained by using all tidal waves together with the wind and the permanent current influence.

Modelled ice drift trajectories for 1 June are shown in Fig. $8 \mathrm{~B}(\mathrm{~b})$ and (c). The wind and ice conditions at this date differ from the event discussed above. The concentration of ice is about $7-9 / 10$ and the wind blows in a southwesterly direction, coinciding with the direction of the permanent current. The trajectories of the ice movements are therefore elongated. The major axis is now about $15 \mathrm{~km}$, which corresponds well with the observed trajectories (Fig. $8 \mathrm{~B}(\mathrm{a})$ )).

The consequence of the joint action of tides, wind and permanent current creates the periodic formation of loops. The twice diurnal divergence and compression (Fig. 9) may explain why the tracks of ice movement live for only 12-13 hours.
The sign of the divergence changes from positive to negative with a variable period from 4 to 16 hours. The channels in the ice cover can exist only when the divergence is positive. If the divergence is negative, the channels will be closed. Intensive freezing may prevent the channels from closing, but this is unlikely to occur in May and June, the months when the satellite pictures where taken. It would be valuable to analyse similar satellite pictures from the winter (freezing) season. Accordingly, performed simulations may at least qualitatively explain the formation of the regularly formed channels in the ice cover caused by grounded icebergs.

\section{References}

Aagard, K., Foldvik, A., Gammelsrød, T. \& Vinje, T. 1983 One-year records of current and bottom pressure in the strait between Nordaustlandet and Kvitøya, Svalbard, 1980-1981. Polar Research 1(2), 107-113.

Aagard, K., Darnall, L., Foldvik, A. \& Tørresen, T. 1985 Fram Strait current measurements 1984-1985. Report no. 63. Dept. of Oceanography, University of Bergen.

Gjevik, B. 1990: Model simulations of tides and shelf waves along the shelves of the Norwegian-Greenland-Barents sea. In Davies, A. M. (ed.): Modelling Marine Systems, vol. I CRC Press Inc.

Gjevik, B. \& Staume, T, 1989: Model simulations of the $\mathrm{M}$ and $\mathrm{K}$ tide in the Nordic Seas and the Arctic Ocean. Tellus $41 \mathrm{~A}$. 73-96.

Kagan, B. A. 1968: Hydrodynamical tidal movements in the sea. Hydrometeoizdat. 219 pp. (in Russian).

Kheysin, D. E. \& Ivchenko, B. O. 1973: A numerical model of tidal ice drift with the interaction between flocs. $I z b$. Acad. Sci. USSR: Atmospheric and Oceanic Physics 9, 420-429 (in Russian).

Kowalik, Z. 1981: A study of the M2 tide in the ice-covered Arctic Occan. Modelling, Identification and Control 2, 201223.

Legenkov, A. P. 1968: On the definition of ice concentration, dispertion and compaction using tidal currents. AARI Issue 285, 215-222 (in Russian).

Nilsen, J. H., McClimans, T. A. \& Løvås 1990: Rift drift in floe flow: ice-berg wakes in Arctic Sea ice. Continental Shelf Research 10(1), 81-86.

Polyakov, I. V. \& Proshutinsky, A. Yu. 1988: Periods of the eigenoscillations of sea level in the Arctic Ocean. Meteorologia and Hydrologia 11, 91-100 (in Russian).

Rothrock, D. A. 1975: The mechanical behaviour of pack ice. Ann. Rev. of Earth and planetary Sci. 3, 317-342.

Tee, K. T. 1976: Tide-induced residual current, a 2-D nonlinear numerical tidal model. Journal of Marine Research 34,603628.

Timokhov, L. A. \& Kheysin, D. E. 1987: Dynamics of the sea ice. Hydrometoizdat, Leningrad. 271 pp. (in Russian).

Zubov, N. N. 1945: Arctic ice. Izd. Glavsevmorputi, Moscow 350 pp. (in Russian). 
